\title{
Implementation of ANFIS based controller on IG wind farm for improved performance
}

\author{
Pragya Sharma, Satbir Singh, Vivek Pahwa \\ Department of Electrical and Electronics, University Institute of Engineering and Technology, India
}

\begin{tabular}{|c|c|}
\hline Article Info & ABSTRACT \\
\hline Article history: & In this paper, the transient performance of a 9-MW Induction Generator (IG) \\
\hline Received Feb 7, 2019 & $\begin{array}{l}\text { wind farm is improved by implementing an Adaptive Neuro Fuzzy Inference } \\
\text { System (ANFIS) based controller on the turbine in MATLAB/SIMULINK }\end{array}$ \\
\hline Revised Apr 12, 2019 & environment using phasor analysis. Initially, the parameters of PI controller \\
\hline Accepted Apr 30, 2019 & $\begin{array}{l}\text { is developed using conventional method. Then, with the help of PI controller, } \\
\text { the ANFIS based controller is trained. This developed controller reduces }\end{array}$ \\
\hline Keywords: & $\begin{array}{l}\text { peak overshoot and settling time of active power and torque-speed } \\
\text { characteristics in contrast to PI controller. Further, the system is linearized }\end{array}$ \\
\hline ANFIS & $\begin{array}{l}\text { and the obtained results in time domain have been validated for stability by } \\
\text { using Pole-Zero plot. }\end{array}$ \\
\hline
\end{tabular}

Copyright $\odot 2019$ Institute of Advanced Engineering and Science. All rights reserved.

\section{Corresponding Author:}

Pragya Sharma,

Department of Electrical and Electronics Engineering,

University Institute of Engineering and Technology,

Panjab University, Sector 25, Chandigarh-160014, India.

Email: pragyasharmauiet@gmail.com

\section{INTRODUCTION}

Renewable energy is becoming a popular source of clean energy these days [1]. Due to its cost efficiency, trivial pollution and continuous supply, they are becoming the latest trend [2]. Wind energy has become a primary non-conventional source of energy with increasing installed capacity and offshore generation [3]. In recent times, efforts have been made to exploit the major environmental benefits of wind energy reaching up to $5.5 \times 10^{5}$-MW of world installed capacity by 2017 and increasing offshore installations.

In today's time, grid connectable systems have assumed importance as they directly export power for usage and void storage necessities [4]. In a grid connected, non-conventional system such as wind turbine, the input energy is intermittent and hence continuously changes with time. Correspondingly, the output power in such system changes with respect to time at every instant. In such a grid connected area, system instability, faults and transients may damage our turbines due to electromagnetic stresses [5]. Therefore, besides generating maximum power from renewable sources, efficient generation of energy is a prime requisite [6].

With the continuously varying wind speed, the output active power also changes. A slight variation in the wind speed may cause the system to become volatile to high forces and speed causing friction in mechanical parts. This demands power control and parameter adjustments which is done by using automatic controllers. Recent studies have proposed a wide range of control algorithms [7]. A PQ controller is used to improve system performance in renewable energy systems to bring output power to a nominal value [8]. However, implementation of such controllers is complex. An effective method for system control is fuzzy logic control instead of conventional PID controllers [7]. A combination of fuzzy inference system and neural networks has evolved as an optimal control method. However, the adjustment of fuzzy membership functions 
through hit and trial is laborious. Therefore, ANFIS is being used for systematic construction of fuzzy rules and membership functions [9].

Besides active power, a system needs reactive power control. With the change in wind speed, the reactive power demand of the system also changes. And therefore, grid control is becoming a necessity with the continuous change in reactive power requirements of the system. An induction generator is excited by an externally connected capacitor bank. The capacitor size varies according to system needs and accordingly becomes bulky and costly and can serve a fixed reactive power demand. Therefore, now-a-days STATCOM is being used for variable reactive power compensation. Besides being capable of providing variable reactive power compensation, STATCOM is a cheap alternative to operator requirements and variable power needs $[10,11]$. A combination of a static capacitor bank and STATCOM serves as an ideal choice for systems where sporadic behavior of input is expected [12].

Continuously varying inputs and surges may introduce transients in the system. It is important to carry out transient analysis to maintain overall security of the system and keep system in operation. Transient stability studies and system monitoring helps in extracting productive energy by limiting voltages, currents and speed. Therefore, in renewable energy systems like wind turbines, transient study assumes prime importance. Transient state analysis can be well performed with MATLAB/SIMULINK environment and MATLAB environment permits us to carry out varied analysis through simulation methods:

- $\quad$ Phasor method

- $\quad$ Discrete method

- Continuous method

All of them have their respective applications and limitations thereby judging their usage in any model. A continuous simulation method is applied for an accurate solution in systems having continuous state. Whereas, a discrete model is used in a discrete model where a state changes at a particular time and remains for some time. Phasor method finds its usage in transient stability analysis for large power systems, motors and generators with long simulations times. It is used to study oscillations and to find simpler algebraic equations representing current and voltage phasors. Nonetheless, it can be applied to linear circuits to calculate phasor changes in voltage and current. It is a fast method however, can be applied only at one frequency [13].

In this paper, the electrical and mechanical performance of an IG wind farm has been improved by implementing an ANFIS based controller in MATLAB/SIMULINK environment. Since the scope of the paper is to conduct transient state study, phasor analysis has been appropriately used to achieve the same. Further, after obtaining results with PI and developed controller, the detailed system model is linearized and stability of system verified using pole-zero plot.

\section{SYSTEM DESCRIPTION AND ITS CONTROLLERS}

A 9-MW wind farm [13], consisting of three 3-MW generation pairs, with its control block has been depicted in Figures 1(a) and 1(b) respectively. The wind turbines are coupled with squirrel cage induction generators. The system is connected to $120 \mathrm{kV}, 60 \mathrm{~Hz}$ grid through a $25 \mathrm{~km}, 25 \mathrm{kV}$ feeder. The stator winding is connected to the grid and a variable-pitch wind turbine drives the rotor. The pitch angle control limits the power flow when the wind speed exceeds the nominal value of $10 \mathrm{~m} / \mathrm{sec}$. The speed ranges between $1 \mathrm{pu}$ and $1.005 \mathrm{pu}$ for unloaded and fully loaded condition respectively. The detailed system parameters have been given in Table 1. The system consists of four basic components i.e. wind turbine, induction generator, reactive power compensation block and control block, each of which has been described. The values of parameters for wind farm are given as shown in Table 1.

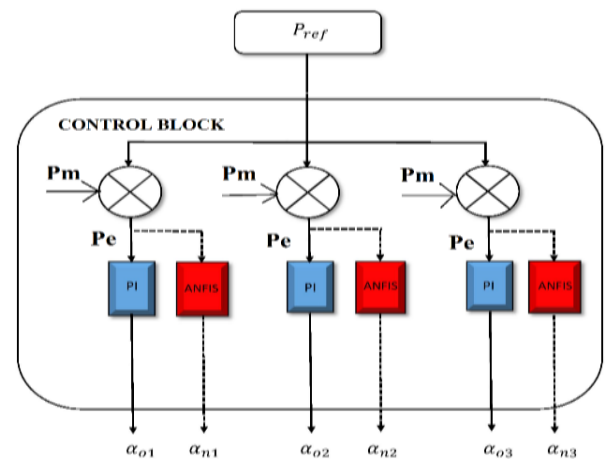

(a) 


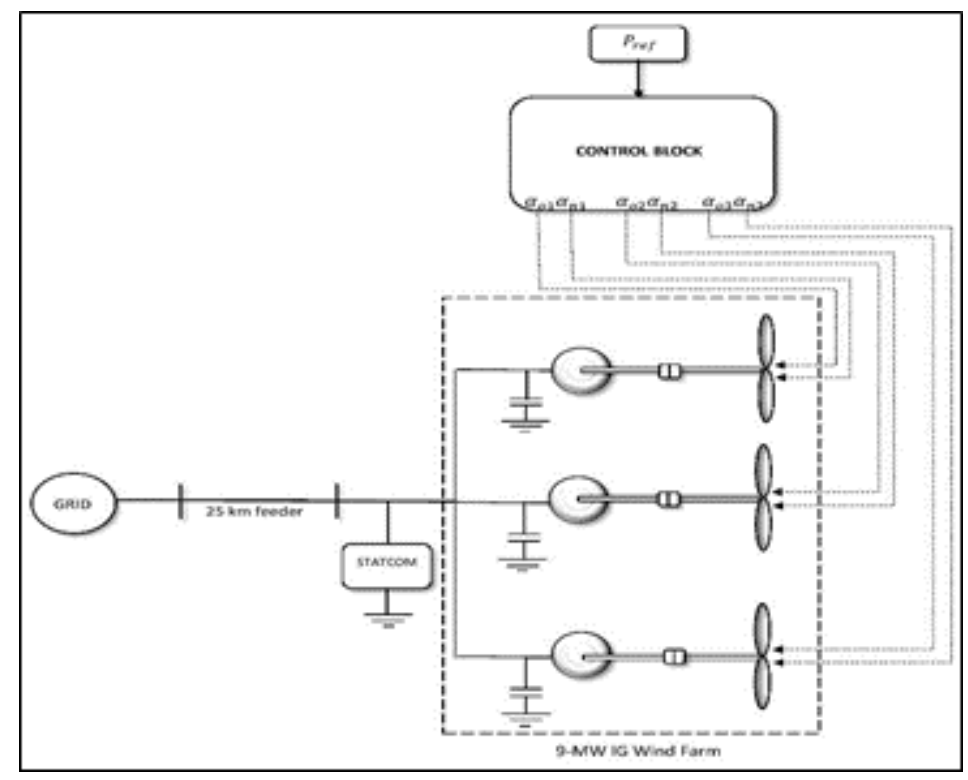

(b)

Figure 1. (a) Diagram representing control block, (b) Grid connections with IG wind farm

\subsection{Wind turbine}

Wind turbines convert wind energy into mechanical power. Wind turns the turbine blades, connected to rotor, which spins the generator to generate electricity. The mechanical output power is given to the induction generator. It converts mechanical output power into electrical power. As discussed earlier, the mentioned system is a 9-MW wind farm consisting of three 3-MW generation sets. Each of the generator set comprises of two 1.5-MW turbines to export power to $120-\mathrm{kV}$ grid. The mechanical output power for the system is given as [14]:

$$
P_{\text {mech }=P} \underset{\operatorname{perf}(x, y) \frac{Z_{\text {area }}}{2}}{ } p V_{w}^{3}
$$

Where,

Mechanical Output power $\quad=P_{\text {mech }}$

Performance coefficient $=P_{\text {perf }}$

Air density $=\mathrm{x}$

Pitch angle of blade $=y$

Area swept by blade $\quad=\mathrm{Z}$

Wind speed $\quad=V_{w}$

Tip speed ratio $\quad=\mathrm{p}$

\subsection{Induction generator}

An induction generator is an alternating current (AC) machine that operates on the principle of induction motors to produce power. The rotor runs faster than synchronous speed with the help of a prime mover. The wind farm uses Squirrel-cage induction generators. Squirrel-cage generators are most commonly used in induction generator applications. They consist of a squirrel-cage rotor which is a cylinder with embedded Aluminium and Copper conductors.

\subsection{Reactive power compensation}

Each pair of 1.5MW turbine demands 400-kvar of reactive power. During steady state, the capacitor banks are capable enough to support reactive power generation. However, during transient state, as the reactive power demand increases, it is compensated by STATCOM. STATCOM is an economic solution to present compensators, around $40 \%$ cheaper than its alternatives [6]. In absence of STATCOM, the voltage at bus drops causing overload of the wind turbine. It maintains a voltage of $25 \mathrm{kV}$ at the connected bus during transient condition.

Int J Rob \& Autom, Vol. 8, No. 2, June 2019 : 94 - 104 


\subsection{Control block}

With the change in system active power, the system demands power control and adjustments. This is achieved by the control block (refer Figure 1(a). The change in power $P_{m}$ is fed to the a comparator and an error signal $P_{e}$ is generated by comparing it with a reference value $P_{r e f}$. The error signal is fed to the controller for system control. The controller is a conventional PI controller which is then replaced by ANFIS based controller to improve system performance. Both PI and ANFIS based controllers have been developed in the next sections to come. With the change in wind speed, the pitch angle change is $\alpha_{o}$ for PI controller and $\alpha_{n}$ for ANFIS based controller.

\section{DESIGN OF PI CONTROLLER}

A conventional PI controller is to be connected for system control. The model is subjected to linear analysis mechanism under control design. For this, the linearization tool is used. The methodology allows us to gather system information and parameters. At first, with linearization of model, we get system transfer function which is as follows:

Let the controller structure be represented by $T_{c}$.

Where, (1-2)

$$
\begin{aligned}
& T_{c}=\frac{n u m}{d e n} \\
& \text { num }=a^{25} s^{25}+a^{24} s^{24}+\ldots \ldots \ldots \ldots .+a^{1} s^{1}+a^{0} s^{0} \\
& \text { den }=b^{27} s^{27}+b^{26} s^{26}+\ldots \ldots \ldots \ldots . .+b^{1} s^{1}+b^{0} s^{0}
\end{aligned}
$$

The value of all coefficients have been presented in Table 2 .

The controller structure is of the type $k_{\text {pro }}+\frac{k_{\text {int }}}{s}[15]$

$T_{c}$ can also be written as :

Consider the plant transfer function to be $\backslash T_{p}$.

The transfer function can also be written in exponential form as [16]:

$$
T_{p}=M_{\text {peak }} e^{j \theta}
$$

Therefore, the transfer function for open loop system becomes $T_{c} T_{p}$.

Let the phase margin for given system be $\emptyset$ and open loop crossover frequency to be.l

With the given phase margin and crossover frequency, open loop transfer function can be given as:

$$
\left(k_{\text {pro }} \frac{j k_{\text {int }}}{\omega}\right) \cdot\left(M_{\text {peak }} e^{j \theta}\right)=e^{j(-180+\varnothing)}
$$

To evaluate $k_{\text {pro }}$ and $k_{\text {int }}$, we solve above (3-4):

$$
\begin{aligned}
& -k_{\text {pro }} \omega M_{\text {peak }} \sin \sin \theta+k_{\text {int }} M_{\text {peak }} \cos \cos \theta=\omega \sin \sin \emptyset \\
& k_{\text {pro }} \omega M_{\text {peak }} \cos \cos \theta+k_{\text {int }} M_{\text {peak }} \sin \sin \theta=-\omega \cos \cos \emptyset
\end{aligned}
$$

From above equations, we find the following (5-4):

$$
\begin{aligned}
& k_{\text {pro }}=\frac{-\cos (\phi-\theta)}{M_{\text {peak }}} \\
& k_{\text {int }}=\frac{\omega \sin (\varnothing-\theta)}{M_{\text {peak }}}
\end{aligned}
$$

With the knowledge of $M_{\text {peak }}, \omega, \varnothing, \theta$, we can calculate the value for $k_{\text {pro }}$ and $k_{\text {int }}$. The values of which have been given in Table 1. Whereas the values of coefficients are given in Table 2 . The design of PI controller is essential for design of the ANFIS based controller. The design of the proposed ANFIS based controller is given in the next section. The various system parameters for model under consideration are as given Table 1 and 2 . The values for coefficients in equations (1) and (2) are given in Table 2. 
Table 1. Parameters of 9-MW wind farm

\begin{tabular}{cc}
\hline Turbine Output Power & $3 \mathrm{MW}$ each \\
\hline Generator inductance & $6.77 \mathrm{pu}$ \\
Turbine Base Wind Speed & $10 \mathrm{~m} / \mathrm{sec}$ \\
$k_{\text {pro }}$ & 5 \\
$k_{\text {int }}$ & 25 \\
Maximum Pitch Angle & $45 \mathrm{deg}$ \\
Fixed Capacitor reactive power & $400 \mathrm{Kvar}$ \\
\hline
\end{tabular}

Table 2. Table for values of coefficients

\begin{tabular}{|c|c|c|c|}
\hline \multicolumn{4}{|c|}{ NUM DEN } \\
\hline Coefficient & Value & Coefficient & Value \\
\hline$a^{25}$ & 81.61 & $b^{27}$ & 1 \\
\hline$a^{24}$ & $1.267 \mathrm{e} 05$ & $b^{26}$ & 1599 \\
\hline$a^{23}$ & $2.366 \mathrm{e} 08$ & $b^{25}$ & $3.055 \mathrm{e} 06$ \\
\hline$a^{22}$ & $2.442 \mathrm{e} 11$ & $b^{24}$ & $3.238 \mathrm{e} 09$ \\
\hline$a^{21}$ & $2.501 \mathrm{e} 14$ & $b^{23}$ & $3.39 \mathrm{e} 12$ \\
\hline$a^{20}$ & $1.887 \mathrm{e} 17$ & $b^{22}$ & $2.618 \mathrm{e} 15$ \\
\hline$a^{19}$ & $1.323 \mathrm{e} 20$ & $b^{21}$ & $1.874 \mathrm{e} 18$ \\
\hline$a^{18}$ & $7.617 \mathrm{e} 22$ & $b^{20}$ & $1.101 \mathrm{e} 21$ \\
\hline$a^{17}$ & $3.899 \mathrm{e} 25$ & $b^{19}$ & $5.756 \mathrm{e} 23$ \\
\hline$a^{16}$ & $1.746 \mathrm{e} 28$ & $b^{18}$ & $2.62 \mathrm{e} 26$ \\
\hline$a^{15}$ & $6.567 \mathrm{e} 30$ & $b^{17}$ & $1.008 \mathrm{e} 29$ \\
\hline$a^{14}$ & $2.281 \mathrm{e} 33$ & $b^{16}$ & $3.543 \mathrm{e} 31$ \\
\hline$a^{13}$ & $6.051 \mathrm{e} 35$ & $b^{15}$ & $9.631 \mathrm{e} 33$ \\
\hline$a^{12}$ & $1.582 \mathrm{e} 38$ & $b^{14}$ & $2.534 \mathrm{e} 36$ \\
\hline$a^{11}$ & $2.594 \mathrm{e} 40$ & $b^{13}$ & $4.286 \mathrm{e} 38$ \\
\hline$a^{10}$ & $4.579 \mathrm{e} 42$ & $b^{12}$ & $7.56 \mathrm{e} 40$ \\
\hline$a^{9}$ & $2.852 \mathrm{e} 44$ & $b^{11}$ & $4.969 \mathrm{e} 42$ \\
\hline$a^{8}$ & $9.907 \mathrm{e} 45$ & $b^{10}$ & $1.879 \mathrm{e} 44$ \\
\hline$a^{7}$ & $2.365 \mathrm{e} 47$ & $b^{9}$ & $4.976 \mathrm{e} 45$ \\
\hline$a^{6}$ & $3.547 \mathrm{e} 48$ & $b^{8}$ & $8.942 \mathrm{e} 46$ \\
\hline$a^{5}$ & $4.069 \mathrm{e} 49$ & $b^{7}$ & $1.259 \mathrm{e} 48$ \\
\hline$a^{4}$ & $3.273 \mathrm{e} 50$ & $b^{6}$ & $1.331 \mathrm{e} 49$ \\
\hline$a^{3}$ & $1.944 \mathrm{e} 51$ & $b^{5}$ & $1.12 \mathrm{e} 50$ \\
\hline$a^{2}$ & $7.83 \mathrm{e} 51$ & $b^{4}$ & $7.165 \mathrm{e} 50$ \\
\hline$a^{1}$ & $1.716 \mathrm{e} 52$ & $b^{3}$ & $3.465 \mathrm{e} 51$ \\
\hline \multirow[t]{3}{*}{$a^{0}$} & $1.438 \mathrm{e} 52$ & $b^{2}$ & $1.184 \mathrm{e} 52$ \\
\hline & & $b^{1}$ & $2.337 \mathrm{e} 52$ \\
\hline & & $b^{0}$ & $1.841 \mathrm{e} 52$ \\
\hline
\end{tabular}

\section{DESIGN OF ANFIS BASED CONTROLLER}

Fuzzy logic control is gaining wide significance as a control technique. Fuzzy logic controllers are gaining importance in terms of improving turbine aerodynamics, improving efficiency and enhancing performance. However, it cannot automatically tune the set of rules. Whereas adaptive systems provide comprehensive training mechanism and can be applied to a wide range of practical systems. This combination of fuzzy inference and adaptive neural networks has emerged as a novel computational method against all of its counterparts [16]. A detailed study on ANFIS has been given in [17, 18] and [19].

The working of adaptive neural methodology is similar to neural networks. It provides information on a set of data by computing membership function parameters, mapped to a set of rules. It maps rules to output characteristics and output characteristics to single valued output or decision. The system is modelled by the fuzzy inference constructed by ANFIS with tuned parameters and training algorithms. Adaptive learning through ANFIS consists of four marked spheres of parameter tuning.

- Parameter adjustment

- Data Identification

- Model validation

- $\quad$ Testing data sets

ANFIS editor GUI helps us to train and test Sugeno-type fuzzy inference system. The editor can be accessed through a MATLAB prompt anfiseditor. The subsequent tasks in ANFIS editor have been explained in [14]. To train the controller with ANFIS GUI, the data is loaded from the PI controller into the editor 
interface. The training data set are collected on the basis of observations and target system. The output of PI is fed into the editor for training ANFIS. Flow chart representing GUI tasks as shown in Figure 2.

A structure can be developed from the loaded data by varying the number of membership functions. The data is repetitively trained according to varied membership functions so as to get an accurate training result. After each training, simulations are run and corresponding data is observed. Figures 3-7 show the developed membership functions, structure and rules obtained for an accurate simulation. Fuzzy if-then rules are associated with membership function used during training. The fuzzy if-then rules for given simulation as shown in Table 3:

- If (input 1 is in $1 \mathrm{mf} 1)$ then (output is out $1 \mathrm{mf} 1)(1)$

- If (input1 is in1mf2) then (output is out1mf2) (1)

- If (input1 is in1 mf3) then (output is out $1 \mathrm{mf} 3)$ (1)

After subsequent training, the data is tested on data sets on which it was not trained. By validating the model, we check the general working capability of Fuzzy logic control on the given system. The scope of the paper is to implement the principle of balance. The control action is performed in order to maintain a nominal value of active power. A PI controlled system was able to maintain power control by changing the pitch angle. However, with the help of ANFIS based controller, a better control action can be performed by a smaller change in pitch angle thereby improving system performance.

Table 3. Specifications for ANFIS

\begin{tabular}{cc}
\hline Parameter & Value \\
\hline No. of inputs & 1 \\
No. of outputs & 1 \\
No. of membership functions & 3 \\
Type of membership function & trimf \\
No. of epoche & 3 \\
Average testing Error & 1.2842 \\
\hline
\end{tabular}

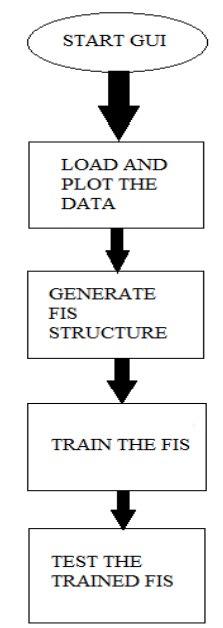

Figure 2. Flow chart representing GUI tasks

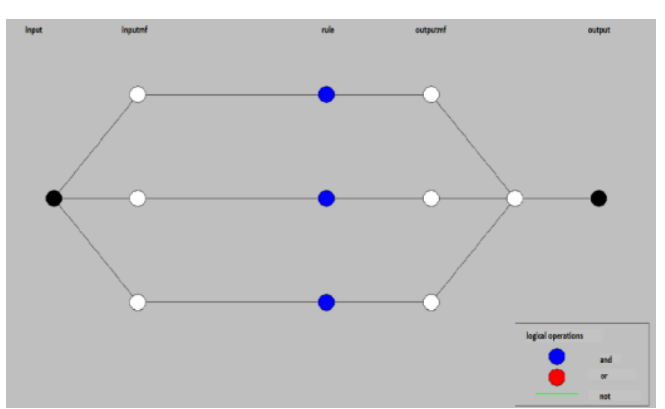

Figure 3. Structure for trained ANFIS

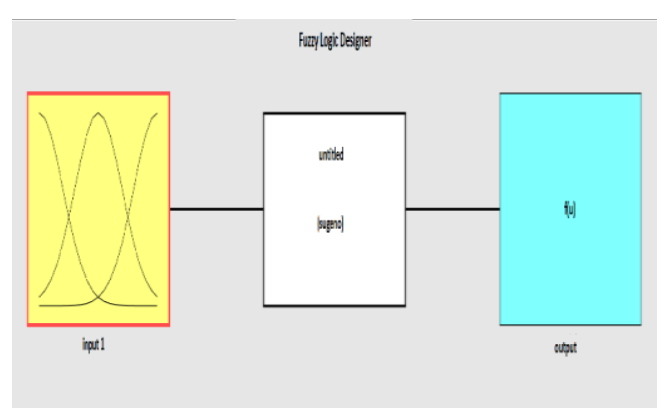

Figure 4. Fuzzy logic designer

Implementation of ANFIS based controller on IG Wind Farm for improved performance (Pragya Sharma) 


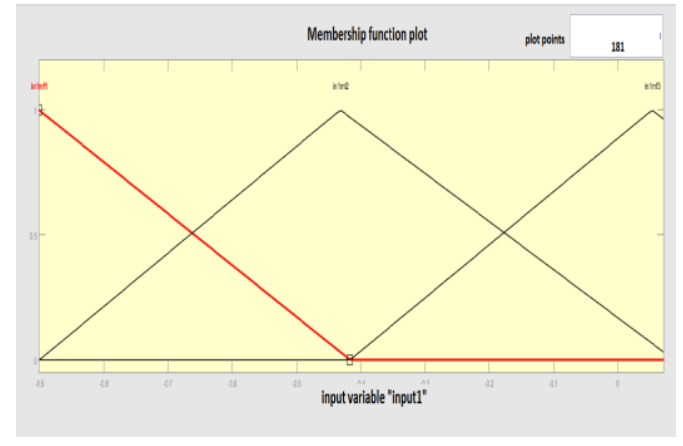

Figure 5. Membership functions for trained data

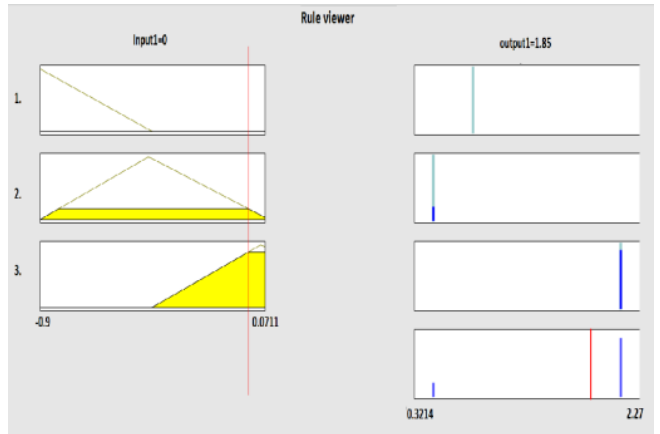

Figure 6. Rule viewer GUI showing membership functions

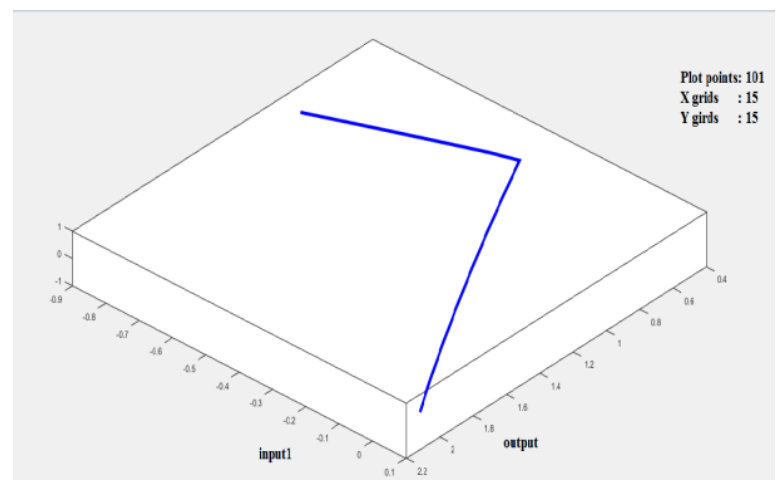

Figure 7. Surface viewer for designed ANFIS

\section{RESULTS AND ANALYSIS}

The model which is analyzed under transient conditions with PI and ANFIS is a 9-MW wind farm. It is simulated for a period of 20 seconds and studied using phasor analysis. The simulation is carried out using solver ode23tb in MATLAB R2015a environment. The wind turbines have a nominal wind speed rating of $10 \mathrm{~m} / \mathrm{s}$. The simulation is performed with applied speed of $8 \mathrm{~m} / \mathrm{s}$ on all the three turbines initially. Then, a change in wind is applied to turbine 1 at $\mathrm{t}=2 \mathrm{sec}$ and the speed changes from $8 \mathrm{~m} / \mathrm{sec}$ to $11 \mathrm{~m} / \mathrm{sec}$. Similarly, wind speed is rammed to $11 \mathrm{~m} / \mathrm{s}$ for turbine 2 and turbine 3 at $4 \mathrm{sec}$ and 6 sec respectively. The Figures (8-13) give the comparative analysis of active power, reactive power, bus voltage, rotor speed and electromagnetic torque with proposed and PI controller.

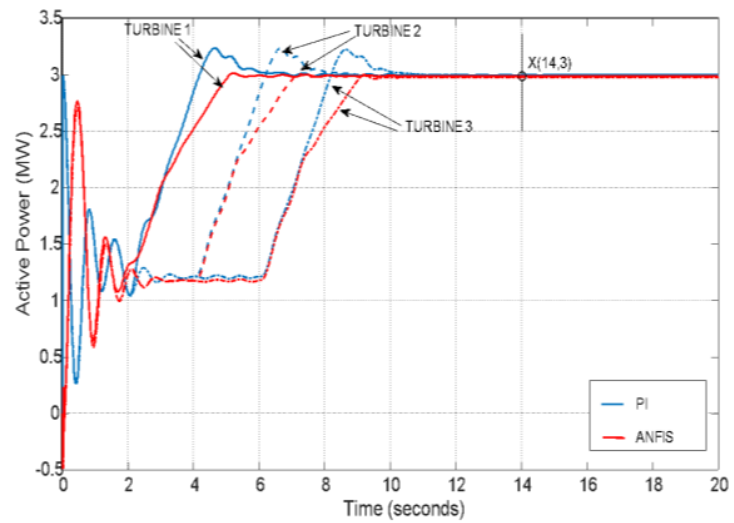

Figure 8. Comparison of output active power of 3 wind turbines with PI and ANFIS based controller

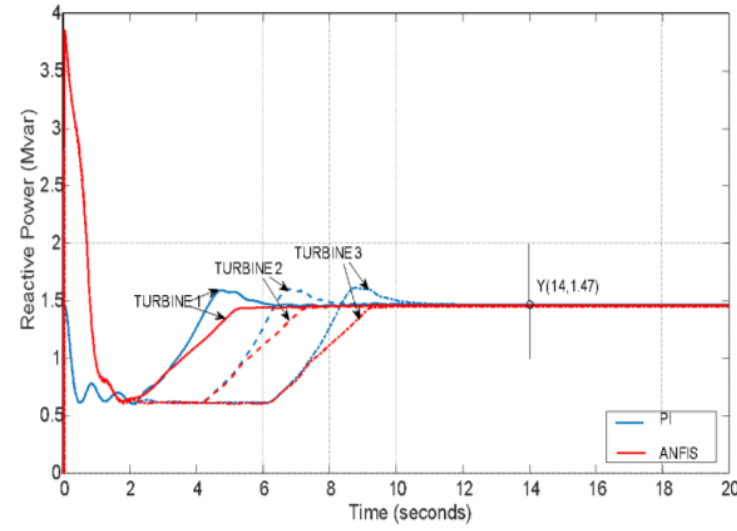

Figure 9. Comparison of output reactive power of 3 wind turbines with PI and ANFIS based controller 


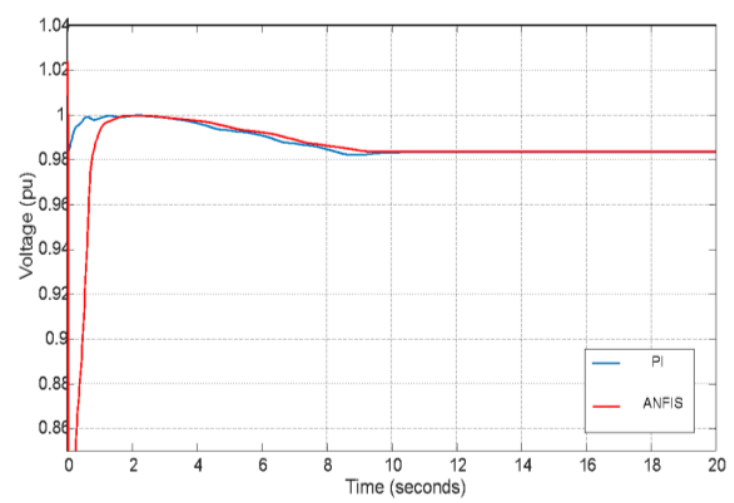

Figure 10. Comparison of bus voltage with PI and ANFIS based controller

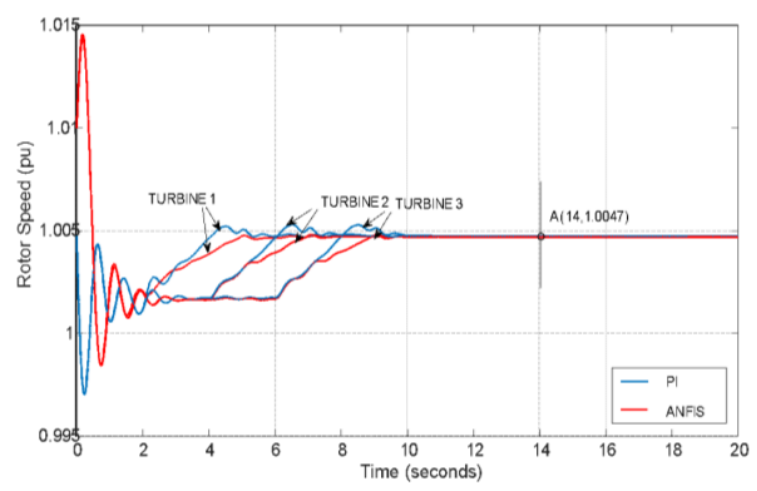

Figure 12. Comparsion of rotor speed of 3 wind turbines with PI and ANFIS based controller

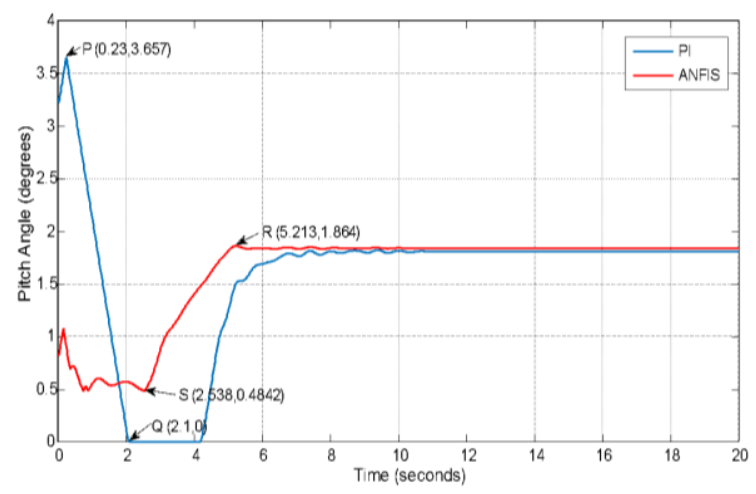

Figure 11. Comparison of pitch angle with PI and ANFIS based controller

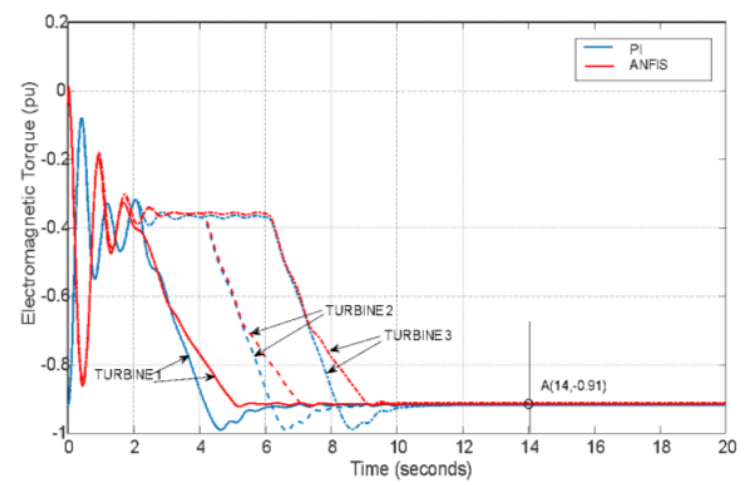

Figure 13. Comparison of electromagnetic torque of 3 turbines with PI and ANFIS based controller

It can be seen from Figure 8 and 9 that the peak overshoot and settling time of active and reactive power are reduced with ANFIS based controller in contrast to PI controller. Alternatively, the comparative analysis (quantitative in nature) of improved performance with the proposed controller is also given in Table 4. In other words, the electrical performance of the system is enhanced. Figure 10 shows the voltage at bus with PI and ANFIS based controller. It can be seen that voltage with the proposed controller shows minor improvement.

It can be seen that for maximum wind change on turbines, the maximum pitch angle change is 3.657 degrees and has been shown as in Figure 11. Using the developed controller, the pitch angle change is calculated to be 1.380 degrees. Therefore, for the same wind change, the mechanical movement of turbine blades is less with the proposed controller in comparison to PI controller. This improves the mechanical performance of the overall system.

Table 4. Comparison of active power of wind farm

\begin{tabular}{ccc}
\hline \multicolumn{3}{c}{ ACTIVE POWER } \\
\hline \multicolumn{3}{c}{ TURBINE 1: } \\
PI & Peak overshoot (MW) & Settling time (seconds) \\
ANFIS & 3.237 & 12.7 \\
& 3.016 & 11.92 \\
TURBINE 2: & \\
PI & Peak overshoot (MW) & Settling time (seconds) \\
ANFIS & 3.239 & 12.47 \\
& 3.011 & 12.18 \\
& TURBINE 3: & \\
PI & Peak overshoot (MW) & Settling time (seconds) \\
ANFIS & 3.227 & 13.72 \\
\hline
\end{tabular}


Figures 12 and 13 show the dynamic behaviour of rotor speed and electromagnetic torque with respect to time. It can be again seen that the rotor speed and electromagnetic torque are settling in minimum time with the use of developed controller in contrast to PI controller. The rotor speed and electromagnetic torque is termed as mechanical parameters of the system.

Figure 14 shows the transient performance of rotor speed and electromagnetic torque. The investigation of these characteristics are necessary for analysing the performance of any electromechanical based system [20]. It is to be noted that the number of oscillations are reduced with the developed controller in contrast to PI controller. It is also to be noted that this Figure gives the performance of turbine 1 only. The similar behaviour is expected for turbines 2 and 3 .

At steady state, it can be seen from Figure 8 and 9 that the turbines output active power and reactive power settle at an operating point $\mathrm{X}$ and $\mathrm{Y}$ given as $(14,3)$ and $(14,1.47)$ respectively. Therefore, when the turbines attain steady state at fully loaded condition, they generate the maximum rated active power of 3-MW. Further, it can be observed from Figure 12 and 13 that when the system attains the steady state operating point $\mathrm{A}$, the ordinates are $(14,1.0047)$ and $(14,-0.91)$ respectively. And these ordinates are replicated in Figure 13 by emitting the time axis. Therefore, in Figure 13, now the operating point $\mathrm{A}$ is having the ordinates $(1.0047,-0.91)$. As this characteristics gives the clear understanding of oscillations.

The detailed non-linear model of single input and single output wind power is converted into linear model using linearization tool of MATLAB. Therefore, the pole-zero plot of this linearized model is shown in Figure 15. It can be seen that all the poles lie on the left hand side of the imaginary axis and therefore the system is stable proving the validity of the work done.

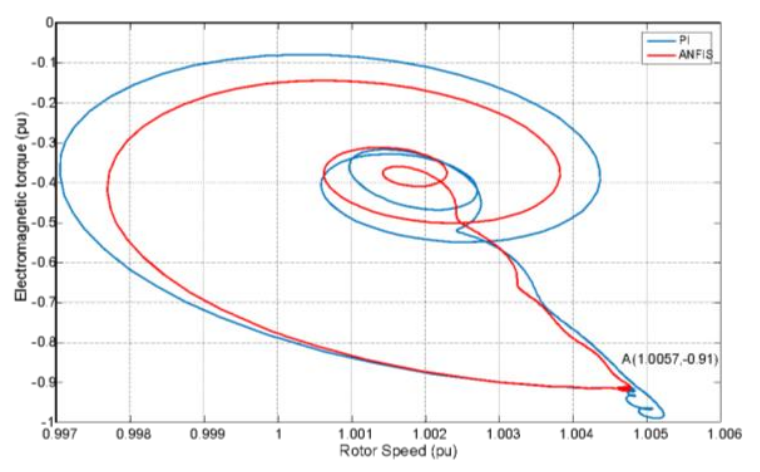

Figure 14. Torque speed characteristics for turbine 1 with PI and ANFIS based controller

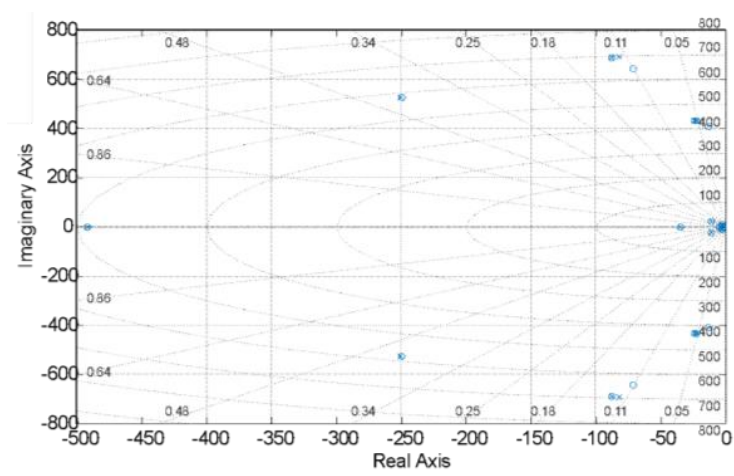

Figure 15. Pole-Zero plot for PI and ANFIS controller

\section{CONCLUSION}

In this paper, the transient performance (electrical and mechanical) of a 9-MW IG wind farm has been improved by implementing ANFIS based controller in contrast to conventional PI controller. An ANFIS based controller has been designed and implemented to improve system performance in contrast to a conventional PI controller. The study has been carried out in MATLAB/SIMULINK R2015a environment with solver ode23tb through phasor analysis. This improvement has been shown with the help of various waveforms like active power, reactive power, voltage, torque and speed. It is concluded that the proposed controller reduces peak overshoot as well as settling time. The stability shown by pole-zero plot, obtained by linearizing the detailed non-linear model proves the validity of the work done.

\section{ACKNOWLEDGEMENTS}

The authors are thankful to Design and Innovation Centre for their immense support throughout the research under "Energy Harvesting and Management Technology". The authors are indeed thankful for financial support and laboratory facilities, vide the letter no. 17-11/2015-PN.1 ,to aid the project. 


\section{REFERENCES}

[1] Z. Wang, B. Yuwen, Y. Lang, and M. Cheng, "Improvement of Operating Performance for the Wind Farm With a Novel CSC-Type Wind Turbine-SMES Hybrid System," IEEE Transactions on Power Delivery, vol. 28, no. 2, pp. 693-703, 2013.

[2] A. S. Chandran, "A Review on Active \& Reactive Power Control Strategy for a Standalone Hybrid Renewable Energy System based on Droop Control," Int. Conf. Power, Signals, Control Comput., pp. 1-10, 2018.

[3] P. Mitra, L. Zhang, S. Member, L. Harnefors, and S. Member, "Offshore Wind Integration to a Weak Grid by VSCHVDC Links Using Power-Synchronization Control : A Case Study,"IEEE Transactions on Power Delivery, vol. 29, no. 1, pp. 453-461, 2014.

[4] M. I. Mosaad, "Model reference adaptive control of STATCOM for grid integration of wind energy systems," IET Electric Power Applications,vol. 12, no. 5 pp. 605-613, 2018.

[5] N. Kaur and V. Pahwa, "Enhanced Performance of Isolated Wind-Diesel ( IW- D ) Hybrid System feeding Heavy Load under various Operating Conditions," Indian Journal of Science and Technology, vol. 9, no. 40, pp. 1-11, October, 2016.

[6] C. Dou, Y. Zheng, D. Yue, Z. Zhang, and K. Ma, "Hybrid model for renewable energy and loads prediction based on data mining and variational mode decomposition," IET Generation, Transmission and Distribution, vol. 12, no. 11, pp. 2642-2649, 2018.

[7] R. Chedid, F. Mrad, M. Basma, "Intelligent control of a class of wind energy conversion systems," vol. 14, no. 4, pp. 1597-1604, 1999.

[8] W. Bai, M. Abedi, K. Y. Lee, "Distributed generation system control strategies with PV and fuel cell in microgrid operation," Control Engineering Practice, Elsevier 53(2106) 184-193, 2016.

[9] J. Mar and F. Lin, "An ANFIS Controller for the Car-Following Collision Prevention System,” IEEE Transactions on Vehicular Technology, vol. 50, no. 4, pp. 1106-1113, 2001.

[10] C. Lassseter, H., Hochgraf, "STATCOM control for operation with unbalanced voltages," IEEE Transactions on Power Delivery, vol. 13, no. 2, pp. 538-544, 1998.

[11] G. S. Singh B., S. S. Murthy, "Analysis and design of STATCOM-based voltage regulator for self-excited induction generators," IEEE Transactions on Energy Conservations, vol. 19, no. 4, pp. 783 - 790, 2004.

[12] E. Sukez and G. Bortolotto, "Voltage Frequency Control of a Self Excited Induction Generator" IEEE Transactions on Energy Conservation," vol. 14, no. 3, pp. 394-401, 1999.

[13] MATLAB: MATLAB 2015a, The Mathworks, Natick, 2015.

[14] A. Khan and V. Pahwa, "Design and Implementation of ANFIS Based Controller on Variable Speed Isolated WindDiesel Hybrid System for Better Performance," American Journal of Electrical and Electronic Engineering, vol. 5, no. 5, pp. 172-178, 2017.

[15] K. Ogata, "Modern Control Engineering," 5th edition, Pearson, 2010.

[16] R. Osorio et al., "Fuzzy Logic Control with Improved Algorithm for Integrated LED Drivers," IEEE Transactions on Industrial Electronics vol. 0046, no. c, 2018.

[17] J. S. R. Jang, "Fuzzy modeling using generalized neural networks and Kalman filter algorithm," Proceeding 9th National Conference. Artificial Intelligence (AAAI-91), pp. 762-767, July 1991.

[18] R. Jang, Jyh-shing. “Input Selection for ANFIS Learning," 5th International Conference, pp. 1493-1499, 1996.

[19] M. B. Djukanovic, M. S. Calovic, B. V. Vesovic and D. J. Sobajic, "Neuro-fuzzy controller of low head hydropower plants using adaptive-network based fuzzy inference system," in IEEE Transactions on Energy Conversion, vol. 12, no. 4, pp. 375-381, Dec. 1997.

[20] P. C. Krause., O. Wasynczuk, S. D. Sudhoff. "Analysis of electrical machinery and drive systems." Second Edition, Wiley Interscience, IEEE Press, 2002.

\section{BIOGRAPHIES OF AUTHORS}

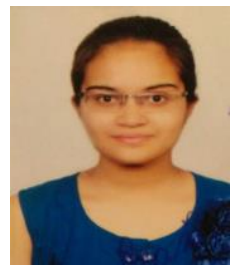

Ms. Pragya Sharma was born in Muzaffarnagar, Uttar Pradesh in 1997. She is currently pursuing her BE degree in Electrical and Electronics from University Institute of Engineering and Technology, Panjab University, Chandigarh. She is interested in electrical machiner, power system and renewable energy.

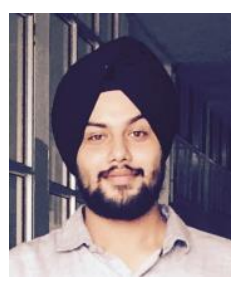

Mr. Satbir Singh was born in Patiala, Punjab in 1996.He is currently pursuing his BE degree in Electrical and Electronics, from University Institute of Engineering and Technology, Panjab University, Chandigarh. He is interested in working with simulations, analysis of electrical machinery and power system 
Dr. Vivek Pahwa was born at Kaithal, Haryana, India in 1974. He received his BE degree from Regional Engineering College, Kurukshetra University, Kurukshetra in 1997. He completed his M. Tech. and PhD. from NIT, Kurukshetra in 2005 and 2013 respectively.He is working in the Department of Electrical and Electronics as an Assistant Professor at University Institute of Engineering and Technology, Panjab University, Chandigarh.His interests include modelling, analysis and simulations of Electrical machines, drives systems, power systems. 